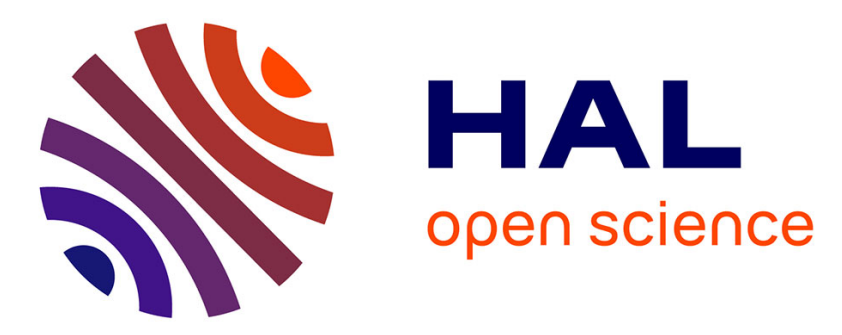

\title{
Soil Water Sensor Based on Standing Wave Ratio Method of Design and Development
}

\author{
Yinli Xu, Weizhong Yang, Zhenbo Li
}

\section{To cite this version:}

Yinli Xu, Weizhong Yang, Zhenbo Li. Soil Water Sensor Based on Standing Wave Ratio Method of Design and Development. 8th International Conference on Computer and Computing Technologies in Agriculture (CCTA), Sep 2014, Beijing, China. pp.720-730, 10.1007/978-3-319-19620-6_78 . hal01420289

\section{HAL Id: hal-01420289 \\ https://hal.inria.fr/hal-01420289}

Submitted on 20 Dec 2016

HAL is a multi-disciplinary open access archive for the deposit and dissemination of scientific research documents, whether they are published or not. The documents may come from teaching and research institutions in France or abroad, or from public or private research centers.
L'archive ouverte pluridisciplinaire HAL, est destinée au dépôt et à la diffusion de documents scientifiques de niveau recherche, publiés ou non, émanant des établissements d'enseignement et de recherche français ou étrangers, des laboratoires publics ou privés. 


\title{
Soil water sensor based on standing wave ratio method of design and development
}

\author{
Yinli $\mathrm{Xu}^{123, \mathrm{a}}$, Weizhong Yang ${ }^{1, \mathrm{~b}}$, Zhenbo $\mathrm{Li}^{123, \mathrm{c}}$ \\ ${ }^{1}$ College of Information \& Electrical engineering; China Agricultural University; Beijing \\ 100083, China; \\ ${ }^{2}$ Key Laboratory of Agricultural Information Acquisition Technology, Ministry of Agriculture, \\ Beijing 100083, China; \\ ${ }^{3}$ Beijing Engineering Center for Advanced Sensors in Agriculture, Beijing 100083, China \\ ajjkeyxu@163.com, ${ }^{b}$ yamantaka.yang@gmail.com, ${ }^{c}$ zhenboli@126.com,
}

\begin{abstract}
Soil moisture is one of the most important parameters in the soil properties, the traditional methods of soil moisture measurement is timeconsuming. And it can't meet the soil moisture measurement's real-time and fast requirements. This paper analyzes the relationship between soil moisture and its dielectric properties, research the standing wave ratio method for measuring soil water content. Firstly, design hardware circuit, plate making, and welding circuit board, then insert the probe into the soil, by measuring the reflection coefficient, we can know the probe impedance which depend on the soil dielectric constant. At last we can find the internal relation between output voltage and soil water content, by measuring the multiple sets of different water content of soil.
\end{abstract}

Keywords: Soil moisture, Standing-wave ratio, Dielectric property

\section{Introduction}

Soil moisture is an important part of the soil, and plays an important role in the growth of crops. Our country is lack of water resources, agricultural water accounts for about $70 \%$ of the total national water, of which more than $90 \%$ for irrigation, the current national average irrigation water utilization rate is only $43 \%$, Unit water output of agricultural products is far lower than developed countries, and so, the water saving potential is very big also. The current water conservation and efficient water use by governments around the world increasingly widespread attention, promote water-saving technologies and equipment is to save water resources, improve the utilization of water resources in an effective way.

Water is not the only one important factor in the growth of crops, and it is an important prerequisite for effective utilization of fertilizer can be crops, particularly effective use of nitrogen fertilizer, if the soil is too dry will result in fertilizer use cannot be fully absorbed by crops, Cause soil salinization. If too much soil moisture, will cause water leakage, Fertilizer with water will penetrate into the groundwater has become an important reason for groundwater contamination, Due to soil structure and 
soil moisture spatial variability, create the different soil water content in the same field, which requires promoting soil moisture monitoring and variable irrigation technology.

Our country is a large agricultural country in the world, seeking fast and efficient soil moisture measurement technology is particularly important. China accounted for $22 \%$ of the world population, while only $8 \%$ of the world's freshwater resources total. Per capita water resources only $2300 \mathrm{~m} 3 / \mathrm{y}$, equivalent to only a quarter of the world average. Is one of the world's water resources per capita the poorest 13 countries, water resources in our country is very poor, on the other hand wasteful and very large, at present, China's annual irrigation water to about 380,000,000,000 $\mathrm{m} 3$, The effective utilization rate of it is only $30 \% \sim 40 \%$, while developed countries reached $70 \% \sim$ $80 \%$, China's per cubic centimeter of water less than $1 \mathrm{~kg}$ of grain production capacity, Advanced countries has amounted to $2.35 \mathrm{~kg}$, one of the reasons for this situation is that there is no an effective soil moisture measurement technology to ensure the implementation of a system of water-saving agricultural technology, So with an urgent need to study in our country to develop a suitable for application in production of soil moisture rapid measurement technology.

The study and implementation of precision agriculture support to solve problems faced in the agricultural production provides the theory and technology. As the main part of the information technology, sensor technology is the important subject in the process of precision agriculture research, is also an important guarantee of realization of soil moisture monitoring and variable irrigation technology. Electronic information experts, soil scientist, agronomists, water conservancy, and some engineers are trying to seek a kind of high performance soil moisture quickly measuring sensor technology. Currently, a variety of soil moisture measurement technology has matured, based on TDR, FDR, and SWR principle dielectric sensor has a more widely used in agriculture, water conservancy, meteorology and other departments and university research. This paper describes a method based on the measurement of soil moisture standing principle.

\section{Methods introduction}

\subsection{Common measurement methods}

(1)Drying method

This is the only way can direct measuring soil moisture, is currently on the international standard method. It is generally believed that traditional drying measured soil moisture value is credible, can be used for other kinds of soil moisture measurement calibration standards. But its drawback is obvious, drying method is time-consuming, laborious, deep sampling is difficult, will destroy the soil sampling.

(2)Tension meter method

Tension meter method is a widely used method to measure soil moisture, and it is measuring the soil matric potential. Due to the relationship between energy and soil 
moisture is very complicated, non-linear, and easily affected by many physical and chemical properties of soil, this method lagged and loopback, affect the measurement speed. The existence of the above defects greatly limits the popularization and application of the method.

(3)Near infrared method

Near infrared reflection method uses the water in the soil resonance absorption characteristics to measure soil water content. Its advantage is that can realize the noncontact measurement of the soil, but only can measure the soil water content, when measuring deep soil moisture we need to slot soil.

(4)Dielectric property law

Soil is composed of soil particles, water and air, a special dielectric, within a certain frequency electromagnetic wave, the dielectric constant of soil particles is about 4, and dielectric constant of soil is about 1 , the dielectric constant of water is about 77 , far more than the air and soil particle dielectric constant, so we can get the water content of soil by measuring the dielectric constant when the soil is under a certain frequency.

There are many other methods to measure the soil moisture, according to the purposes of the research on soil moisture and the need of agricultural production and ecological environment construction, corresponding measurement method can be used.

\subsection{Standing wave method measuring principle}

Standing wave ratio method, also known as the impedance method or amplitude domain reflection method, it is based on radio frequency technology in soil moisture measuring method of standing wave ratio principle, Experiment shows that the change of the three states of mixture dielectric constant Ka can be cause significant change of standing wave ratio on a transmission line. It measured the dielectric constant of soil by measuring the impedance of the probe in soil media. Signal source sends Electromagnetic wave, which spread along the transmission line, in the joint of transmission lines and soil probe due to the reflection impedance mismatches occur, the reflected wave and the incident wave to form a standing wave in the transmission line.

Therefore, the reflection coefficient is determined by measuring the voltage at both ends of the transmission line, and then we can know the impedance of soil probe. While the geometry of the probe is determined, probe impedance depends on the dielectric constant of the soil, and dielectric constant of the soil is mainly affected by soil moisture, so we can achieve the purpose of measuring soil water content by measuring the impedance of the probe.

This method has the advantage of high precision measurement, Fast response, and it is not sensitive to electromagnetic interference, Can be used long-term embedment fixed monitoring or instant insert using. All circuit integration within the sensor probe, using flexible, sensor output is the standard analog signals, can be connected to any general analog acquisition equipment. But precision is less than TDR, due to the low working frequency, the general is $100 \mathrm{MHZ}$, it is greatly influenced by soil types, this is also a measure of this article will focus on the study.

The structure principle block diagram is as follows 


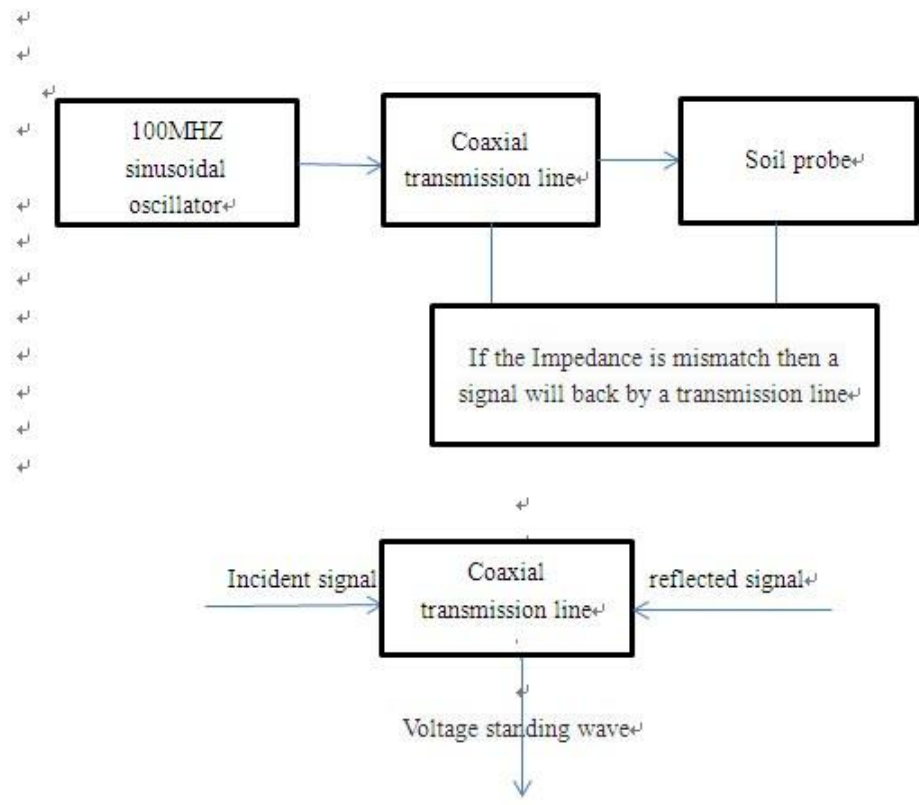

Fig.1. Structure principle diagram

\subsection{The soil dielectric constant relationship with the soil moisture content}

Soil dielectric constant has close relation with soil moisture content, because the dielectric constant of soil particles, water and air difference is very big. Dielectric constant of air is 1 , dry soil dielectric constant is $3 \sim 7$, free water in the temperature of $20^{\circ} \mathrm{C}$ the dielectric constant is 80.36 . Therefore the different proportion of a certain volume of water in the soil, There will be significant changes in the dielectric constant. In 1980 found that soil volumetric water content and dielectric constant relations expressed by a 3 a number of empirical formula, but as a result of various types of soil in our country, and different basic physical and chemical properties of soil, therefore, the dielectric constant is affected by many factors, to reduce the error of the general formula, china Agricultural University, through the study of several typical Chinese soil permittivity and moisture relations, fitting a new $\theta_{W} \varepsilon_{\mathrm{r}_{\mathrm{r}}}$ concise model:

$$
\theta_{\mathrm{v}}=0.1219 \varepsilon_{\mathrm{r}}^{0.5}-0.1846
$$

Soil is composed of water and air, solid porous medium, where the water dielectric constant of about 80 , solid dielectric constant is about 4 , while air dielectric constant is about 1 . So that, the dielectric constant of aqueous soil should be mainly decided by the water. By measuring the dielectric constant of the soil can achieve the goal of measuring soil volumetric moisture content. 
Standing wave method of measuring soil moisture by measurement of standing wave ratio on a transmission line can achieve the goal of measuring soil volumetric moisture content. For a long time, sensor consistency and soil texture, the influence of temperature influence on measuring result has been a soil moisture measuring method and measuring technology research and the major technical difficulties. According to soil texture type of SWR soil moisture sensor influence degree of the measurement result, in china agricultural university east campus sensor and testing technology research institute do a lot of laboratory performance test and comparative study, and in the German federal academy of agricultural sciences' institute of manufacturing engineering, has carried on the comparative study on the performance of different soil moisture sensor. Performance analysis shows that the type of SWR soil moisture sensor measurement results is affected by soil texture is not obvious, not only has good consistency, and its performance was comparable to similar foreign sensor.

\section{The design of experiment}

\subsection{The introduction of development platform}

Altium Designer is the original Protel software developers Altium launch of the integration of electronic product development system, main run on Windows operating system. The software through the schematic design and circuit simulation, PCB map editor, automatic wiring topology logic, output signal integrity analysis and design techniques such as perfect fusion. Provides designers with a new design solution, the designer can easily design, familiar with the software will make the quality and efficiency of circuit design is greatly increased.

\section{2 $\mathrm{T}$ he describes of hardware circuit}

The use of Altium Designer is to design of circuit principle diagram, mainly divided into the signal source, transmission line and probe part.

\subsubsection{Signal source part}

The system uses the signal source $100 \mathrm{MHZ}$ oscillating sine wave generator. 


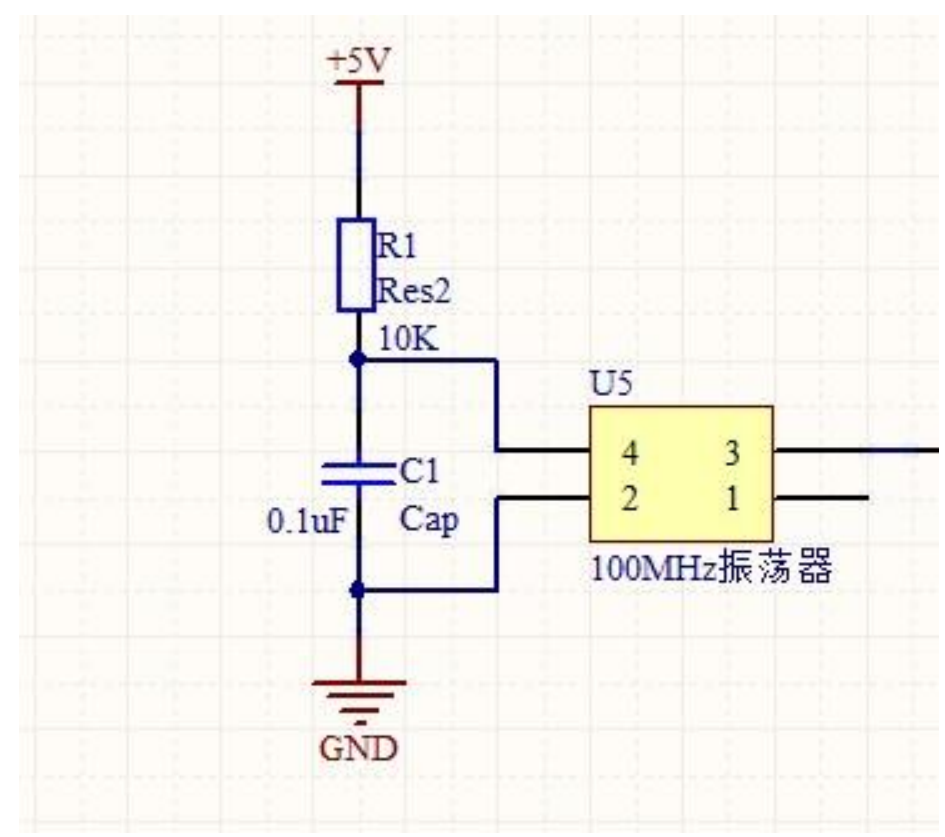

Fig.2. Signal Source

\subsubsection{Coaxial transmission line}

When the signal source produces an incident signal $\mathrm{V}_{0}$

$$
V_{0}=\mathrm{a} \sin 2 \pi \mathrm{ft}
$$

Where $\mathrm{a}$ is the amplitude, $\mathrm{f}$ is the frequency of oscillation and $\mathrm{t}$ is the time since some arbitrary instant, then the reflected component at the same point, then the reflected component at the same point will be

$$
V_{0}=a \sin 2 \pi f t+a \rho \sin \pi f\left(t-\frac{2 l}{V_{p}}\right)
$$

Where 1 is the length of the transmission line, $V_{p}$ is the velocity of propagation of signals along the line and pis called reflection coefficient .If the transmission line is made $\mathrm{V}_{\mathrm{p}} / 4 \mathrm{f}$ in length, then this reduces to

$$
\left.V_{0}=a \sin \mathbb{Z} f t \boldsymbol{\rho} \sin \tau 2 f \neq \quad a+b \quad\right) \sin \text { (4) }
$$

At that point can be concluded that peak voltage as the biggest, at the same time on the transmission line, the superposition of incident wave and reflected wave form a standing wave, the standing wave of peaks and troughs in the ends of the coaxial cable.

Standing wave makes voltage amplitude of each point on a transmission line is different

$$
\Delta U=2 a \rho=2 a \frac{\left(Z_{l}-Z_{0}\right)}{\left(Z_{l}+Z_{0}\right)}
$$


Where $\mathrm{z}_{1}$ is the probe impedance, and $\mathrm{z}_{\mathrm{o}}$ is that of the transmission line.

And the standing wave on a transmission line rate can be expressed as follows

$$
\Gamma=\frac{1-\rho}{1+\rho}
$$

In this way, through the measurement of standing wave ratio on a transmission line can achieve the goal of measuring soil volumetric moisture content.

\subsubsection{The probe}

By China agricultural university, institute of information and electrical engineering professor Wang Yiming leading group of the successful development of science and technology based on stainless steel type standing wave ratio of the soil moisture sensor probe has three kinds of different specifications, probe diameter is $6 \mathrm{~mm}$, probe spacing is $4 \mathrm{~cm}$, around the probe length is $4 \mathrm{~cm}$, intermediate probe lengths ranging $10,15,20 \mathrm{~cm}$ to meet the requirements for measuring the soil of different depth. This study was conducted through three probes collected, when the probe geometry must probe impedance depends on the soil dielectric constant, and the dielectric constant of the soil mainly affected by soil water content, so by measuring the dielectric constant of the soil can achieve the goal of measuring soil volumetric moisture content.

\subsection{The soil sample making}

Take enough for calibration of soil spread in a cool, ventilated place dry, until can sieve, will be the first ground soil, with soil sieve pore diameter $3 \mathrm{~mm}$, then use soil sieve pore diameter of $1 \mathrm{~mm}$, for soil samples. The soil sample was flat out on the stainless steel tray, in $105 \sim 110^{\circ} \mathrm{C}$ oven drying to constant weight 24 hours a day, then remove them in the dryer to cool to room temperature $\left(20^{\circ} \mathrm{C}\right)$.

From the dry soil to nearly saturated 10 kinds of quality water content of soil sample, use electronic weigh and drying quality for Gs soil samples respectively and water quality for $\mathrm{Gw}$, the soil mixed with water and stir well, in a sealed plastic bag in the balance after 24 hours, stir again, then placed in sealed plastic bags rebalancing 24 hours, You can get quality water content for the $\theta \mathrm{m}$ series of soil sample.

\subsection{Weighing method to measure soil column the actual moisture content}

From each soil column of about $50 \mathrm{~g}$ of soil samples, respectively in the aluminum box, with a sense of $0.1 \mathrm{~g}$ electronic weighing soil total quality $\mathrm{w}_{\mathrm{o}}$, drying in an oven at $105 \sim 110{ }^{\circ} \mathrm{C}$ for 24 hours to constant weight, cooling to room temperature $\left(20^{\circ} \mathrm{C}\right)$ in the dryer, weighing dry soil quality $\mathrm{w}_{\mathrm{s}}$. The experimental data fill in the table 1. 


\subsection{Measuring the sensor output voltage}

Insert the SWR soil moisture sensor into each standard soil samples in the soil column, the output voltage $\mathrm{V}$ is measured with a digital voltmeter, and record in table 2, $3 \sim 5$ in each soil column can be repeated measurement points.

Table 1. Soil moisture measurement data

\begin{tabular}{cccccc}
\hline NO. & $\begin{array}{c}\text { Soil quality } \\
(\mathrm{g})\end{array}$ & $\begin{array}{c}\text { dry soil quality } \\
(\mathrm{g})\end{array}$ & $\begin{array}{c}\text { water quality unit } \\
(\mathrm{g} / \mathrm{g})\end{array}$ & $\begin{array}{c}\text { weight volumetric } \\
(\mathrm{g} / \mathrm{cm} 3)\end{array}$ & $\begin{array}{c}\text { water content } \\
(\mathrm{cm} 3 / \mathrm{cm} 3)\end{array}$ \\
\hline 1 & 13.63 & 13,56 & 0.005 & 1.244 & 0.006 \\
2 & 14.12 & 13.65 & 0.034 & 1.254 & 0.043 \\
3 & 16.81 & 15.71 & 0.070 & 1.257 & 0.088 \\
4 & 18.35 & 16.18 & 0.134 & 1.249 & 0.125 \\
5 & 20.34 & 17.58 & 0.157 & 1.251 & 0.197 \\
6 & 18.20 & 15.04 & 0.210 & 1.451 & 0.305 \\
7 & 26.34 & 21.93 & 0.201 & 1.511 & 0.302 \\
8 & 24.26 & 19.36 & 0.253 & 1.399 & 0.354 \\
9 & 29.35 & 22.51 & 0,304 & 1.402 & 0.426 \\
10 & 27.15 & 20.23 & 0.342 & 1.337 & 0.458 \\
\hline
\end{tabular}

Table 2. Sensor measurement data

\begin{tabular}{|c|c|c|c|c|c|c|}
\hline \multirow[t]{2}{*}{ NO. } & \multicolumn{5}{|c|}{ The sensor output voltage } & \multirow{2}{*}{$\begin{array}{c}\text { The average } \\
\text { (v) }\end{array}$} \\
\hline & 1 & 2 & 3 & 4 & 5 & \\
\hline 1 & 0.030 & 0.027 & 0.024 & 0.026 & 0.028 & 0.027 \\
\hline 2 & 0.325 & 0.322 & 0.328 & 0.326 & 0.325 & 0.325 \\
\hline 3 & 0.524 & 0.533 & 0.532 & 0.535 & 0.525 & 0.530 \\
\hline 4 & 0.719 & 0.714 & 0.718 & 0.722 & 0.724 & 0.719 \\
\hline 5 & 1.214 & 1.219 & 1.215 & 1.213 & 1.214 & 1.215 \\
\hline 6 & 1.579 & 1.543 & 1.538 & 1.543 & 1.563 & 1.533 \\
\hline 7 & 1.907 & 1.903 & 1.893 & 1.91 & 1.903 & 1.903 \\
\hline 8 & 2.211 & 2.202 & 2.198 & 2.189 & 2.203 & 2.201 \\
\hline 9 & 1.850 & 1.855 & 1.846 & 1.855 & 1.845 & 1.850 \\
\hline 10 & 1.916 & 1.950 & 1.909 & 1.909 & 1.911 & 1.910 \\
\hline
\end{tabular}

\section{Results and Discussion}

\subsection{The experiment results analysis}

In Table 2 obtained from the average value of the sensor output voltage $\mathrm{V}$ as independent variables, and based on the actual volumetric water content of the obtained in table $1 \theta \mathrm{m}$ as the dependent variable, the calculated results in table 3 , using least squares regression equation.

Table 3. Sensor experimental data

\begin{tabular}{lccrcc}
\hline NO. & 1 & 2 & 3 & 4 & 5 \\
\hline$\Theta v(\mathrm{~cm} 3 / \mathrm{cm} 3)$ & 0.006 & 0.043 & 0.088 & 0.125 & 0.197 \\
$\mathrm{~V}(\mathrm{v})$ & 0.027 & 0.325 & 0.530 & 0.719 & 1.215 \\
\hline NO. & 6 & 7 & 8 & 9 & 10 \\
\hline$\Theta \mathrm{v}(\mathrm{cm} 3 / \mathrm{cm} 3)$ & 0.305 & 0.302 & 0.354 & 0.426 & 0.458 \\
\hline
\end{tabular}




\begin{tabular}{llllll}
\hline $\mathrm{V}(\mathrm{v})$ & 1.533 & 1.903 & 2.201 & 1.850 & 1.910 \\
\hline
\end{tabular}

Elected to take linear function relation is the function of regression curve type, get regression curve shown in figure 3 as follows:

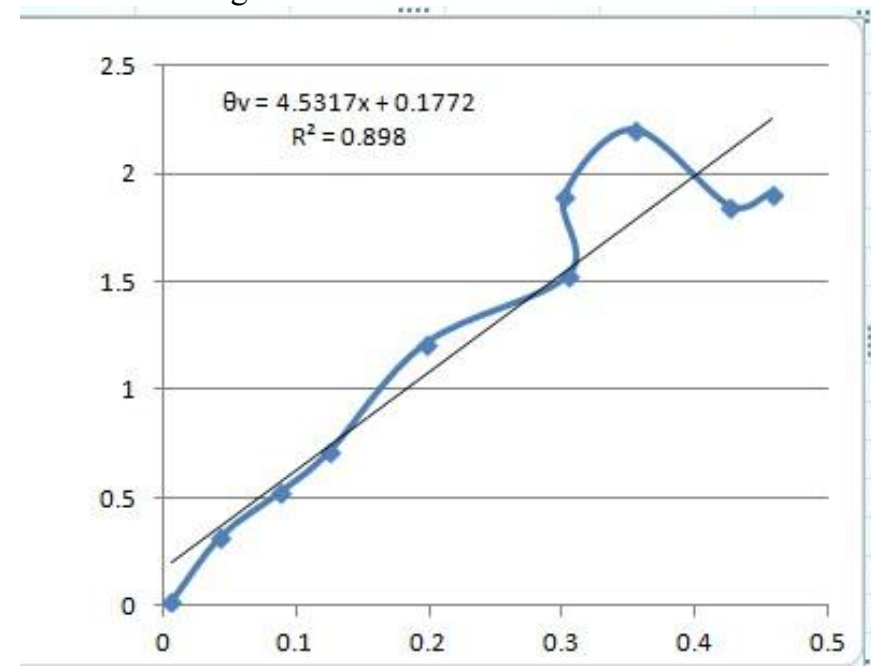

Fig.3. Linear regression curve of soil moisture sensor

When choosing a cubic polynomial for regression function type, the regression curve is shown in figure 4:

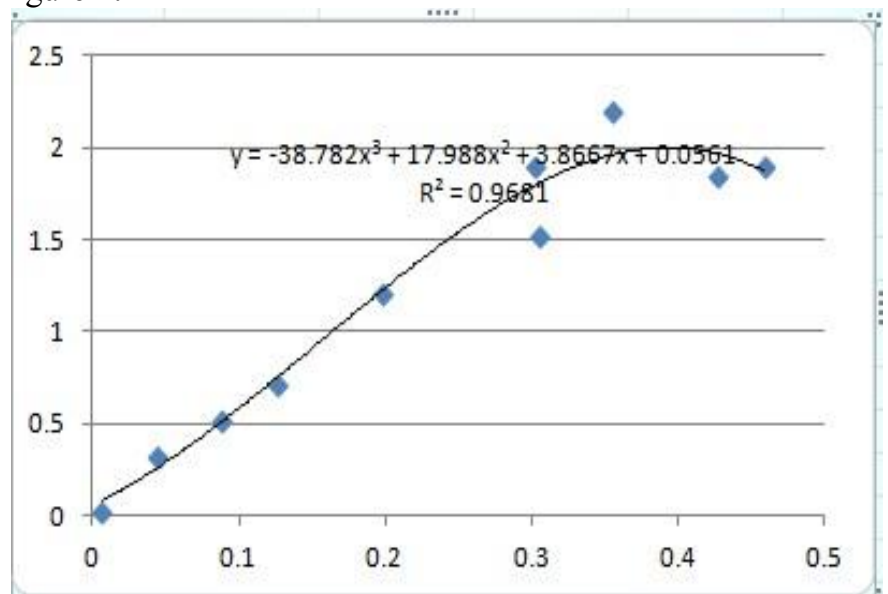

Fig.4. Three regression curve of soil moisture sensor

Compare two curve, curve fitting of three times better than linear, linear regression equation of relative coefficient $\mathrm{R} 2=0.9681$, greater than the correlation coefficient of linear equation, so the fit of the regression equations of three times to far better than the linear regression equation, and has a high significance and accuracy. 


\section{Conclusions}

By analyzing the data from experiment, proving that a standing wave method of the principle of water content of soil moisture sensor is a good relationship with the voltage value curve, is a kind of high performance soil volumetric water content measurement method.

1. This paper starting from the basic principle of electromagnetic wave interaction with the media, through the theoretical analysis of the characteristics of the soil dielectric demonstrates the dielectric method to quickly measure the soil moisture content is a kind of high sensitive wide applicable affected by spatial soil physical and chemical characteristics of spatial variation of small fast measurement method.

2. Design scheme of the method of soil column experiment, through the experiment and regression analysis, we establish the static mathematical model of SWR type moisture sensor. In the pattern measurement, the correlation between the measured value well.

\section{Acknowledgment}

This research is financially supported by the National Science and Technology Support (2012BAD35B07)

\section{References}

1.W. C. Bausch, H. R. Duke, D. F. Heem ann; assessing and mapping the plant nitrogen status in irrigation corn; Precision Agriculture 97.

2. Knight JH. Sensitivity of time domain reflectometry measurements to lateral variations in soil water content [J]. Water Resources Research, 1992, 28(9).

3. Roth K, Schulin R, Fluhler H, et al. Calibration of time domain reflectometry for water content measurement using a composite dielectric approach [J]. Water Resour. Res, 1990, 26(10):2267-2273.

4. Topp G, Davis J. Measurement of soil water content using time-domain reflectrometry (TDR): a field evaluation [J]. Soil Science Society of America Journal, 1985, 49(1):19.

5. Berlin P. Kwok, Stuart O. Nelson, Ezekiel Bahar. Time-Domain Measurements for Determination of Dielectric Properties of Agricultural Materials [J].IEEE transaction on instrumentation and measurement, VOL.IM-28, No2, 1979, 6.

6. Mullins C E ; Mandiringana O T ; Nisbet T R ; Aitken M N The design limitations, and use of a portable tensiometer. Journal of Soil Science 1986, 37: 691-700

7. Wheater H S ; Langan S J ; Miller J D ; Ferrier R C The determination of hydrological flow paths and associated hydrochemistry in forested catchments in Central Scotland. Forest Hydrology and Watershed Management Symposium, Vancouver, August 1987

8. Bell J P Neutron probe practice. Institute of Hydrology Report No. 19, 1973

9. Wellings S R ; Bell J P ; Raynor R J The use of gypsum resistance blocks for measuring soil water potential in the field. NERC Rep. No. 92, 1985 
10. Dean T J; Bell J P; Baty A J B Soil moisture measurement by an improved capacitance technique. 1-sensor design and performance. Journal of Hydrology 1987, 93: 67 - 78

11. Yanuka, M; Topp G C; Zegelin S; Zebchuk W D Multiple reflection and attenuation of time domain reflectometry pulses: theoretical considerations for applications to soil and water . Water Resources Research 1988, 24 (7): 939 - 944

12. Curtis L F; Trudgill S The measurement of soil moisture. Technical Bulletin of the British Geomorphological Research Group 1974, N. 13 